\title{
Distribution of Rutin and Protodioscin in Different Tissue Parts of Asparagus (Asparagus officinalis L.)
}

\author{
Satoru Motoki \\ Faculty of Agriculture, Meiji University, 1-1-1 Higashimita, Tama-ku, \\ Kawasaki, Kanagawa 214-8571, Japan
}

Tianli Tang, Takumi Taguchi, and Ayaka Kato

Graduate School of Agriculture, Meiji University, 1-1-1 Higashimita, Tamaku, Kawasaki, Kanagawa 214-8571, Japan

\section{Hiromi Ikeura}

Faculty of Life and Environmental Science, Shimane University, 1060, Nishikawatsu, Matsue, Shimane 690-8504, Japan

\section{Tomoo Maeda \\ Faculty of Agricultural and Life Science, Hirosaki University, 3 Bunkyocho, Hirosaki, Aomori, 036-8561, Japan}

Additional index words. differences among plant part, fern, HPLC, nonusable parts, open field culture, resources of functional components, storage roots

\begin{abstract}
Asparagus is a popular vegetable rich in healthy functional components. Asparagus spears are known to contain a large amount of rutin, which has been found to possess anti-inflammatory, antitumor, and antibacterial/viral properties, and protodioscin, which is an antitumor substance and present in the bottom parts $(8 \mathrm{~cm}$ from the cut end). However, the process of its production leaves fern in the aboveground parts and roots in the underground parts as significant amounts of nonusable parts, and this issue should be solved. This study was conducted to examine the distributions of rutin and protodioscin, representative functional components in different parts of asparagus. The results suggested that large amounts of rutin were noted in the cladophylls and storage roots (brown and epidermis), and the protodioscin content was high in the buds, the soilcovered section of the spear, and the rhizome. A significant amount of rutin was detected in the aboveground parts, which is consistent with the results of previous studies, but it was also found in the storage roots. The largest amount of protodioscin was found in the buds, as well as in young fruits and seeds of the aboveground parts. Injury by continuously cropping asparagus may be associated with high rutin content in the storage roots of asparagus.
\end{abstract}

Asparagus (Asparagus officinalis L.) is a perennial plant belonging to the Asparagaceae family and is a popular vegetable consumed in many different areas of the world (Benson, 2012). It can be easily divided into edible and inedible parts. It is necessary to solve the issue of large amounts of nonusable parts that are generated during the time of summer growth and postharvest residue. Although only a small portion of the cladophylls of asparagus, harvested in the autumn season, is used as cladophylls powder, most of the rest is put back into the soil or disposed of; the amount is estimated to be $\approx 130,000$ t per year in Japan.

\footnotetext{
Received for publication 12 Apr. 2019. Accepted for publication 16 July 2019

This work was supported by JSPS KAKENHI Grant Number 18K05929.

S.M. is the corresponding author. E-mail: motoki@ meiji.ac.jp.

This is an open access article distributed under the CC BY-NC-ND license (https://creativecommons.org/ licenses/by-nc-nd/4.0/).
}

In Japan, the spears of harvested asparagus are cut to $\approx 25 \mathrm{~cm}$ in length before shipment (Motoki, 2003; Motoki et al., 2008; Yasuda et al., 2015). Residues from harvested asparagus, including the $\approx 2$-cm-long hard plant parts excised from the base of the spears (lignified spears), account for $10 \%$ of the total shipment (Yasuda et al., 2015), and most of residues are discarded because they are unmarketable. It is necessary to use residues from harvested asparagus effectively and to reduce the costs of their disposal to increase farmers' income (Yasuda et al., 2015). A previous study conducted by Rodríguez et al. (2005) suggested that the base of asparagus spears (lignified spears) contained a large amount of phenols. In addition, when asparagus spears are processed into canned products in the food industry, residues from the production process are discarded, which causes environmental pollution and a waste of useful components or resources (Fan et al., 2015). Zhao et al. (2011) proposed the recycling of asparagus waste as supplements in the food and pharma- ceutical industries. Fan et al. (2015) reported that five antioxidant compounds (ferulic acid, kaempferol, quercetin, rutin, and isorhamnetin) could be identified from nonusable parts of asparagus and the nonusable parts could be used as nutritional supplements.

The functional components of asparagus have attracted increasing attention for adding high value to agricultural products recently. Asparagus spears contain abundant functional components, such as saponin and phenol carboxylic acids (Chin et al., 2002; Hartung et al., 1990; Wang et al., 2003). The representative functional components of asparagus include rutin (Chin et al., 2002; Maeda et al., 2005) and protodioscin (Brueckner et al., 2010; Chin et al., 2002; Lee et al., 2010; Maeda et al., 2012; Schwarzbach et al., 2006; Wang et al., 2003). Rutin has antiinflammatory and antihypertensive effects in animal experiments (Hellerstein et al., 1951; Selloum et al., 2003), and biological effects such as suppression of capillary weakness in humans (Griffith et al., 1944). Tsushida et al. (1994) reported that $75 \%$ of the antioxidant activity of asparagus is derived from rutin. Based on these findings, asparagus should be promoted as a rutin source, and cultivation techniques to increase the rutin content of asparagus may be developed in the future. On the other hand, principal factors influencing the quality of white asparagus spears are softness, sweetness, and bitterness (Brueckner et al., 2010; Hoberg et al., 2008; Maeda et al., 2012). According to Kawano et al. (1975), the bitterness of white asparagus is derived from saponin. Protodioscin, a typical saponin characterized by its pharmacological activity, is included in white asparagus spears (Brueckner et al., 2010; Chin et al., 2002; Lee et al., 2010; Maeda et al., 2012; Schwarzbach et al., 2006; Wang et al., 2003). Protodioscin was cytotoxic to some human cancer cell lines in vitro (Hu and Yao, 2002; Hibasami et al., 2003), and also has aphrodisiac properties (Gauthaman et al., 2002) and improved sexual function in animal experiments (Gauthaman et al., 2003). In previous studies by the authors, functional components of asparagus in different cultivation conditions revealed the following: Rutin was included only in green asparagus, and protodioscin was included only in white asparagus cultivated using the blanching with soil method (Motoki et al., 2012b). The cladophylls of asparagus cultivated in hydroponic systems in plant factories contained not only rutin but also protodioscin, which is not present in the spears of green asparagus (Motoki et al., 2012b). Fresh asparagus spears commonly discarded if their length is out of specifications, also contain a large amount of rutin, and spears that have not been harvested at the optimum time may be useful components or resources of rutin (Motoki et al., 2012a). Unlike cladophylls, strong growthinhibitory activity was observed in storage roots (Motoki et al., 2006)

Few reports are available on the active use of the cladophylls and storage roots as useful 
functional components or resources. In addition, the detailed distributions of rutin and protodioscin, as well as the influence of their cultivation and environmental conditions have not been clarified. However, the nonusable parts of asparagus with weak growth-inhibitory activity can be used as mineral elements or reused as fertilizer components for the following year. Furthermore, if the cladophylls and the storage roots, or nonusable parts of asparagus, can be used as useful component resources, this will not only reduce the amount of waste, or plant residues generated during production, but also help to solve the problem of replanting failure (Motoki et al., 2006), which will significantly influence production settings.

To investigate the possibility of use of nonusable parts of asparagus, we analyzed the distribution of representative functional components (rutin and protodioscin) in each part of asparagus.

\section{Materials and Methods}

Cultivation method. The tested material was 6-year-old ' $U C 157 \mathrm{~F}_{1}$ ' cultivated under a long-term harvest production system in Iijima-machi, Kami-ina-gun, Nagano prefecture. UC157 $F_{1}$, a cultivar of green asparagus, is the most common cultivar in Japan, with a short dormant period and high yields. Cultivation conditions were as follows: long. $138^{\circ} \mathrm{E}$, lat. $36^{\circ} \mathrm{N}$, and height of $720 \mathrm{~m}$ above sea level, alluvial clay loam, $\mathrm{pH} 6.0,0.1 \mathrm{dS} \cdot \mathrm{m}^{-1}$ electrical conductivity, and $3.3 \%$ humus content. The planting pattern was a single row with row width of $150 \mathrm{~cm}$, bed width of $80 \mathrm{~cm}$, and $30 \mathrm{~cm}$ inrow distance $(22,222$ plants/ha). Chemical fertilizer $(200 \mathrm{~N}-200 \mathrm{P}-200 \mathrm{~K})$ was applied before planting, before the permanent planting of 1-year-old plants and before sprouting of 2- to 6-year-old plants. Supplement application $(50 \mathrm{~N}-50 \mathrm{~K})$ was provided every 2 weeks from June to August every year. Plants were watered only by rainfall. To prevent lodging, plants were supported by ridging, stems were supported with stakes, and lower branches were cut back to $50 \mathrm{~cm}$ from the ground. All other cultural practices followed the standard procedure of Nagano prefecture (Motoki, 2003; Motoki et al., 2008).

Samples. Samples required for each experiment were taken from 25 different plant parts of 6-year-old asparagus (Table 1, Fig. 1), and immediately frozen at $-40{ }^{\circ} \mathrm{C}$, except for samples for water content investigation.

Water content. The water content was determined by comparing the weight before and after drying for $2 \mathrm{~d}$ in a drying oven (FC610; Toyo Engineering Works, Tokyo, Japan) at $70{ }^{\circ} \mathrm{C}$. Three sets of three samples were analyzed for each part of asparagus.

Rutin and protodioscin content. Rutin and protodioscin were extracted from frozen samples, respectively. The samples of 18 different plant parts were pulverized for analysis. Rutin and protodioscin were extracted from $50 \mathrm{mg}$ of freeze-dried powder with $1 \mathrm{~mL}$ of $70 \%$ ethanol according to the modification method of Maeda et al. (2010, 2012) and Nikaido et al. (2014). A highperformance liquid chromatography system (HPLC; Laboratory Solutions system; Shimadzu, Kyoto, Japan) equipped with an evaporative light scattering detector (ELSDLTII detector; Shimadzu) and a photodiode array detector (SPD-M20A; Shimadzu) were used for quantification. HPLC conditions were as follows: $1.0 \mathrm{~mL} \cdot \mathrm{min}^{-1}$ flow rate, $40{ }^{\circ} \mathrm{C}$ column temperature, a Waters Symmetry $\mathrm{C} 18$ column $(4.6 \times 250 \mathrm{~mm}$; Nihon Waters K. K., Tokyo, Japan) with a security guard cartridge $(3.0 \times 4.6 \mathrm{~mm}), 0.1 \%$ trifluoroacetic acid: acetonitrile-water (by volume) mobile phase with a gradient condition, 354-nm wavelength of a photodiode array detector (Maeda et al., 2010, 2012; Nikaido et al., 2014). A calibration curve was prepared using external standard rutin solution (Wako Pure Chemical Industries, Osaka, Japan) and protodioscin solution (ChromaDex Inc., Los Angeles, CA), and the rutin and protodioscin content were calculated from the peak area, respectively. Three sets of three samples were analyzed for each part of asparagus.

Statistical analysis. The Tukey-Kramer test was performed using Statcel software Version 2 (OMS Publishing, Saitama, Japan) to identify significant differences $(P<0.05)$ in the water content, and rutin and protodioscin contents of different plant parts.

\section{Results and Discussion}

Water content. Table 1 reports the differences in water content among different asparagus parts. The water content ranged from 93.5 [base of the spear (harvest in summerautumn)] to $6.5 \%$ (seed). Asparagus young fruit, spears, rhizome, and storage root (white, yellow, and brown) water contents were $\approx 90 \%$ or higher than other plant parts. Seed, storage roots (epidermis), and ripe fruit had lower water content than other plant parts.

Distribution of rutin content. Table 1 shows differences in the rutin content among different parts of asparagus. The rutin content in cladophylls $\left[20.456 \mathrm{mg} \cdot \mathrm{g}^{-1}\right.$ dry weight (DW)] was six times higher than the rutin content in the spear tip (3.160 $\mathrm{mg} \cdot \mathrm{g}^{-1} \mathrm{DW}$ ), which was consistent with the results of previous studies (Maeda, 2008; Motoki et al., 2012b). Although the rutin content in the main stem (cortex) was not detectable, that in the main stem (epidermis) was $9.718 \mathrm{mg} \cdot \mathrm{g}^{-1} \mathrm{DW}$. This result suggests that the main stem, as well as the cladophylls, may be effectively used as sources of rutin. On the other hand, the rutin content in the spear tip and base (harvest in spring) was 3.160 and $0.766 \mathrm{mg} \cdot \mathrm{g}^{-1} \mathrm{DW}$, respectively. The rutin content was higher in the spear tip and lower in the base of the spear, which was consistent with the results of previous studies (Maeda, 2008; Maeda et al., 2010; Motoki et al., 2012b; Yasuda et al., 2015). The rutin content in spears covered with soil was not detectable. Al- though the rutin content of asparagus was high in the aboveground parts (Motoki et al., 2012b), 3.008 and $3.242 \mathrm{mg} \cdot \mathrm{g}^{-1} \mathrm{DW}$ of rutin was measured in the storage roots (brown and epidermis), amounts equivalent to levels in the tip spear. As asparagus stocks are growing, the color of its storage roots changes from white to yellow and brown (S. Motoki, unpublished data), and its growth-inhibitory activity increases (Motoki et al., 2006). According to the results of this study, the rutin content in the white, yellow, and brown storage roots were $0.243,1.116$ and $3.008 \mathrm{mg} \cdot \mathrm{g}^{-1} \mathrm{DW}$, respectively; rutin content increases as asparagus stocks age.

When storage roots of asparagus are left in the soil, inhibitory substances are released that cause problems with replanting (Motoki et al., 2006; Yeasmin et al., 2013, 2014; Young and Chou, 1985). Some asparagus fields in Japan were spoiled because effective measures to solve the replant problem were not implemented. Although replanting failure can be prevented by removing all storage roots from the field before replanting, no method to detoxify or to use the removed roots has been developed. Maeda (2008) suggested that the rutin content of asparagus spears is similar to that of buckwheat. Buckwheat has strong growth-inhibitory activity (Zahida et al., 2002) and rutin contained in buckwheat is a causative agent for allelopathy (Golisz et al., 2007; Kalinova and Vrchotava, 2009). The results of this study show large amounts of rutin were included in the storage roots (brown and epidermis) of asparagus; therefore, rutin may be associated with injury by continuous cropping asparagus.

Distribution of protodioscin content. Table 1 shows differences in the protodioscin content among different parts of asparagus. The results show that the protodioscin content is also high in the young fruit and the seed (3.792 and $5.487 \mathrm{mg} \cdot \mathrm{g}^{-1} \mathrm{DW}$, respectively), whereas other measured aboveground plant parts had very low protodioscin levels. The protodioscin content in the base of the spear was $0.061 \mathrm{mg} \cdot \mathrm{g}^{-1} \mathrm{DW}$, but, protodioscin was not detected in the spear tip, which is consistent with previous studies (Maeda et al., 2012; Motoki et al., 2012b). The base of spears (lignified spears) is usually cut off and discarded before shipment (Yasuda et al., 2015); it contains large amounts of protodioscin, as suggested by the present and other studies (Lee et al., 2010; Maeda, 2008; Maeda et al., 2012; Motoki et al., 2012b; Wang et al., 2003). The protodioscin content in the buds was the highest $\left(7.514 \mathrm{mg} \cdot \mathrm{g}^{-1} \mathrm{DW}\right)$, and the content in the basal portion of the spears covered with soil and of rhizome was 3.870 and 3.022 $\mathrm{mg} \cdot \mathrm{g}^{-1} \mathrm{DW}$, respectively. In addition to the underground parts of asparagus, these specific aboveground parts also may be effectively used as resources of protodioscin.

The results of this study suggest that nonusable parts of asparagus can be resources of useful components. In particular, cladophylls and the fern can be sources of rutin, 
Table 1. Differences in the water, rutin, and protodioscin content among different asparagus plant parts.

\begin{tabular}{|c|c|c|c|c|c|}
\hline & Asparagus parts & Sampling time & Water content $(\%)$ & Rutin content $\left(\mathrm{mg} \cdot \mathrm{g}^{-1} \mathrm{DW}\right)$ & Protodiosin content $\left(\mathrm{mg} \cdot \mathrm{g}^{-1} \mathrm{DW}\right.$ \\
\hline \multirow{7}{*}{$\begin{array}{l}\text { Aboveground } \\
\text { parts }\end{array}$} & Cladophylls & 10 June 2012 & $71.9 \mathrm{j}^{\mathrm{z}}$ & $20.456 \pm 0.693^{\mathrm{y}} \mathrm{a}$ & $\mathrm{ND}^{\mathrm{x}}$ \\
\hline & Second lateral branch & 10 June 2012 & $70.9 \mathrm{j}$ & $5.655 \pm 0.453 \mathrm{c}$ & $0.027 \pm 0.001 \mathrm{f}$ \\
\hline & Main stem (whole) & 10 June 2012 & $83.5 \mathrm{fgh}$ & $2.431 \pm 0.221 \mathrm{ef}$ & $0.027 \pm 0.001 \mathrm{f}$ \\
\hline & Main stem (epidermis) & 10 June 2012 & $63.4 \mathrm{k}$ & $9.718 \pm 0.196 \mathrm{~b}$ & $0.046 \pm 0.006 \mathrm{f}$ \\
\hline & Male flower & 27 May 2012 & $85.2 \mathrm{defg}$ & $4.095 \pm 0.158 \mathrm{~cd}$ & $0.088 \pm 0.006 \mathrm{f}$ \\
\hline & Female flower & 27 May 2012 & 84.9 efg & - $^{\mathrm{w}}$ & - \\
\hline & Seed $^{\mathrm{v}}$ & 21 May 2012 & $6.5 \mathrm{~m}$ & ND & $5.487 \pm 0.228 b$ \\
\hline \multirow[t]{4}{*}{ Spear } & Tip of spear (harvest in spring) & 2 May 2012 & $89.6 \mathrm{bc}$ & $3.160 \pm 0.219 \mathrm{de}$ & ND \\
\hline & $\begin{array}{l}\text { Tip of spear (harvest in } \\
\text { summer-autumn) }\end{array}$ & 25 June 2012 & $91.9 \mathrm{ab}$ & - & - \\
\hline & Base of spear (harvest in spring) & 2 May 2012 & $93.2 \mathrm{a}$ & $0.766 \pm 0.130 \mathrm{gh}$ & $0.061 \pm 0.014 \mathrm{f}$ \\
\hline & $\begin{array}{l}\text { Base of spear (harvest in } \\
\text { summer-autumn) }\end{array}$ & 25 June 2012 & $93.5 \mathrm{a}$ & - & - \\
\hline parts & Rhizome & 10 June 2012 & $79.8 \mathrm{hi}$ & ND & $3.022 \pm 0.188 \mathrm{~d}$ \\
\hline & Storage root (white) & 10 June 2012 & $89.9 \mathrm{bc}$ & $0.243 \pm 0.028 \mathrm{~h}$ & $1.141 \pm 0.140 \mathrm{e}$ \\
\hline & Storage root (yellow) & 10 June 2012 & $89.7 \mathrm{bc}$ & $1.116 \pm 0.025 \mathrm{fgh}$ & $1.509 \pm 0.086 \mathrm{e}$ \\
\hline & Storage root (brown) & 10 June 2012 & $88.4 \mathrm{~cd}$ & $3.008 \pm 0.272 \mathrm{de}$ & $0.942 \pm 0.126 \mathrm{e}$ \\
\hline & Storage root (epidermis) & 10 June 2012 & $63.7 \mathrm{k}$ & $3.242 \pm 0.341 \mathrm{de}$ & $0.028 \pm 0.002 \mathrm{f}$ \\
\hline
\end{tabular}

${ }^{2}$ According to the Tukey-Kramer test, any two means within a column not followed by same letter are significant at $P<0.05$ (n $=3-6$ ). Statistical analysis was conducted after arcsine conversion of water content.

${ }^{\mathrm{y}}$ Means $\pm \mathrm{SE}$

${ }^{\mathrm{x}} \mathrm{ND}=$ not detectable

w_ indicates not tested.

${ }^{\mathrm{v}}$ Seeds produced in 2011, freeze-drying on 21 May 2012.

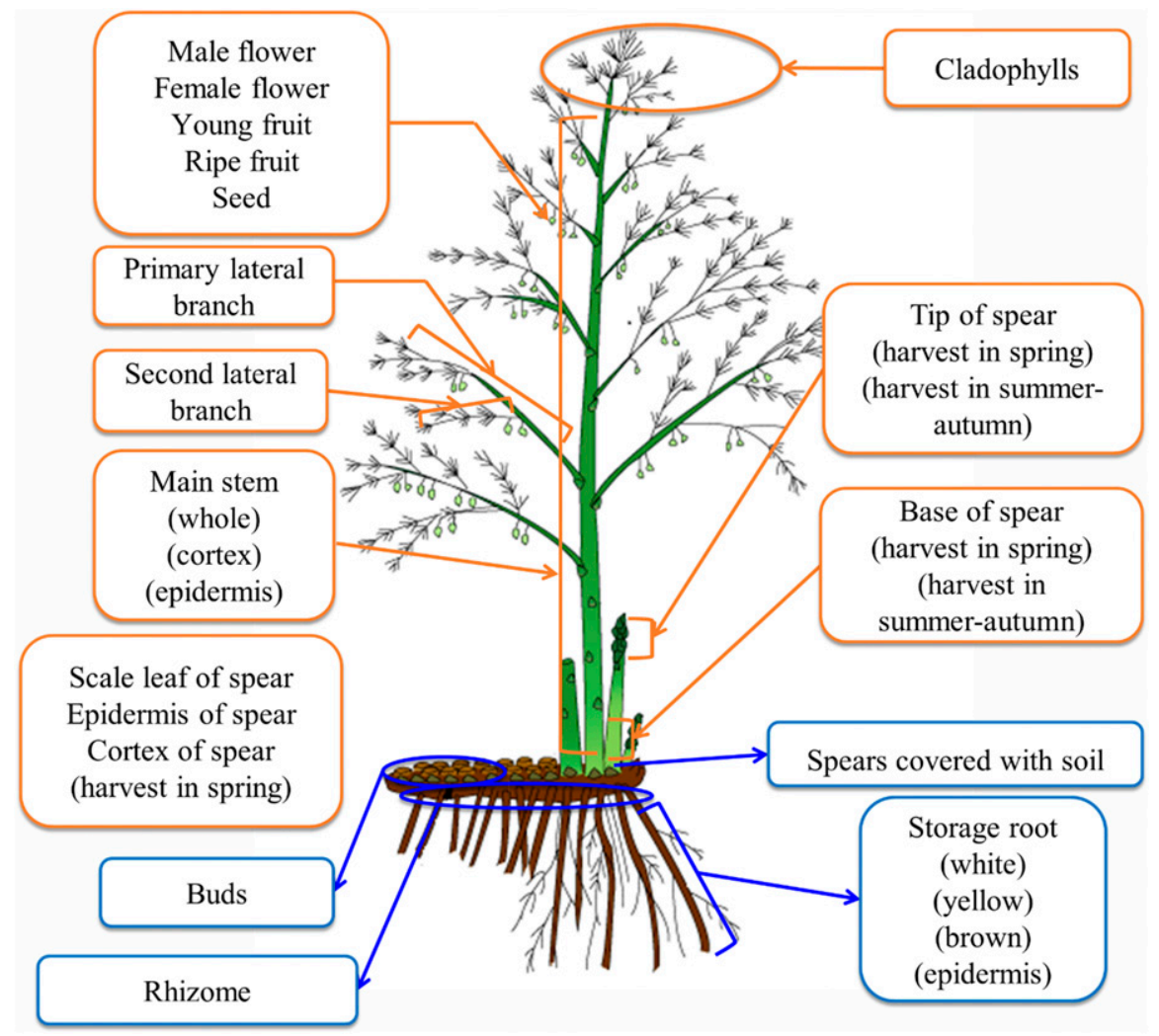

Fig. 1. Sampling parts of asparagus.

and young fruit and seeds are sources of protodioscin. Large amounts of protodioscin are noted in the buds, and the soil-covered section of the spear and the rhizome; the rutin content is high in the storage roots (brown and epidermis). The findings of this study may create value for nonusable parts of asparagus. However, to examine the possi- bility of using nonusable parts of asparagus, it is necessary to examine differences in the mineral contents of elements and plant biomass. In addition, cultivation conditions may influence the contents of useful components contained in nonusable parts of asparagus. Based on the findings from this study, further research will examine differences in rutin and protodioscin content among cultivars of asparagus, how cultivation techniques increase functional components content, and suggest new methods for using nonusable parts of asparagus.

\section{Literature Cited}

Benson, B.L. 2012. 2009 update of the world's asparagus production areas, spear utilization and production periods. Acta Hort. 950:87100.

Brueckner, B., A. Schwarzbach, and R. Schroter. 2010. Correlation between sugar and saponin contents and sensory attributes of white asparagus. J. Verbr. Lebensm. (J. Consumer Protection and Food Safety) 5:305-311.

Chin, C.K., S.A. Garrison, C.T. Ho, and M.T. Huang 2002. Functional elements from asparagus for human health. Acta Hort. 589:223-241.

Fan, R., F. Yuan, N. Wang, Y.X. Gao, and Y.X. Huang. 2015. Extraction and analysis of antioxidant compounds from the residues of $A s$ paragus officinalis L. J. Food Sci. Technol. 52:2690-2700.

Gauthaman, K., P.G. Adaikan, and R.N.V. Prasad. 2002. Aphrodisiac properties of Tribulus Terrestris extract (protodioscin) in normal and castrated rats. Life Sci. 71:1385-1396.

Gauthaman, K., A. Ganesan, and R.N.V. Prasad. 2003. Sexual effects of Puncturevine (Tribulus 
terrestris) extract (protodioscin): An evaluation using a rat model. J. Altern. Complement. Med. 9:257-265.

Golisz, A., B. Lata, S.W. Gawronski, and Y. Fujii. 2007. Specific and total activities of the allelochemicals identified in buckwheat. Weed Biol. Mgt. 7:164-171.

Griffith, J.Q., Jr., J.F. Couch, and M.A. Lindauer. 1944. Effect of rutin on increased capillary fragility in man. Proc. Soc. Expt. Biol. Med. 55:228-229.

Hartung, A.C., M.G. Nair, and A.R. Putnam. 1990. Isolation and characterization of phototoxic compounds from asparagus (Asparagus officinalis L.) roots. J. Chem. Ecol. 16:1707-1718.

Hellerstein, H.K., J.L. Orbison, S. Robbard, M. Wilburne, and L.N. Katz. 1951. The effect of rutin in experimental malignant hypertension. Amer. Heart J. 42:271-283.

Hibasami, H., H. Moteki, K. Ishikawa, H. Katsuzaki, K. Imai, and K. Yoshioka. 2003. Protodioscin isolated from fenugreek (Trigonella foenumgraecum L.) induces cell death and morphological change indicative of apoptosis in leukemic cell line H-60, but not in gastric cancer cell line KATO III. Intl. J. Mol. Med. 11:23-26.

Hoberg, E., D. Ulrich, and C. Wonneberger. 2008. Proposal for a flavor standard-sensory profiles of European white Asparagus officinalis L. cultivars. Acta Hort. 776:239-245.

$\mathrm{Hu}, \mathrm{K}$. and X. Yao. 2002. Protodioscin (NSC-698 796): Its spectrum of cytotoxicity against sixty human cancer cell lines in an anticancer drug screen panel. Planta Med. 68:297-301.

Kalinova, J. and N. Vrchotava. 2009. Level of catechin, myricetin, quercetin and isoquercitrin in buckwheat (Fagopyrum esculentum Moench), changes of their levels during vegetation and their effect on the growth of selected weeds. J. Agr. Food Chem. 57:2719-2725.

Kawano, K., K. Sakai, H. Sato, and S. Sakamura. 1975. A bitter principle of asparagus: Isolation and structure of furostanol saponin in asparagus storage root. Agr. Biol. Chem. 39:1999-2002.

Lee, E.J., K.S. Yoo, and B.S. Patil. 2010. Development of a rapid HPLC-UV method for simultaneous quantification of protodioscin and rutin in white and green asparagus spears. J. Food Chem. 75:703-709.

Maeda, T. 2008. Chemical components and freshness retention of asparagus, p. 189-199. In: S. Motoki, K. Inoue, and T. Maeda (eds.). High quality, high yield techniques for asparagus cultivation [in Japanese]. Nousangyoson Bunka Kyokai, Tokyo, Japan.

Maeda, T., K. Honda, T. Sonoda, S. Motoki, K. Inoue, T. Suzuki, K. Oosawa, and M. Suzuki. 2010. Light condition influences rutin and polyphenol contents in asparagus spears in the mother-fern culture system during the summer-autumn harvest. J. Jpn. Soc. Hort. Sci. 79:161-167.

Maeda, T., T. Jishi, A. Komura, H. Hasegawa, K. Narita, K. Honda, and T. Yamaguchi. 2012. Methyl jasmonate treatment enhanced protodioscin biosynthesis in white asparagus ( $A s-$ paragus officinalis L.) spears. J. Jpn. Soc. Hort. Sci. 81:337-342.

Maeda, T., H. Kakuta, T. Sonoda, S. Motoki, R. Ueno, T. Suzuki, and K. Oosawa. 2005. Antioxidation capacities of extracts from green, purple, and white asparagus spears related to polyphenol concentration. HortScience 40:1221-1224.

Motoki, S. 2003. Working convenience notebook of asparagus [in Japanese]. Nousangyoson Bunka Kyokai, Tokyo, Japan. p. 1-155.

Motoki, S., H. Kitazawa, T. Kawabata, H. Sakai, K. Matsushima, and Y. Hamauzu. 2012a. Rapid rutin accumulation during spear elongation in asparagus. HortScience 47:599-602.

Motoki, S., H. Kitazawa, T. Maeda, T. Suzuki, H. Chiji, E. Nishihara, and Y. Shinohara. 2012b. Effects of various asparagus production methods on rutin and protodioscin contents in spears and cladophylls. Biosci. Biotechnol. Biochem. 76:1047-1050.

Motoki, S., K. Matsunaga, T. Maeda, and T. Kutsuzawa. 2008. Selection of asparagus cultivars for cold areas of Japan. Acta Hort. 776: 357-366.

Motoki, S., E. Nishihara, H. Kitazawa, S. Hiradate, and Y. Shinohara. 2006. Participation of allelopathy in injury due to continuous cropping of asparagus (Asparagus officinalis L.) in alluvial soil. Hort. Res. Jpn. 5:431-436 [in Japanese with English abstract].

Nikaido, K., T. Jishi, T. Maeda, T. Suzuki, and H. Araki. 2014. Quality change of asparagus spears stored with snow cooling. J. Jpn. Soc. Hort. Sci. 83:327-334.

Rodríguez, R., S. Jaramillo, R. Guillén, A. Jiménez, J. Fernández-Bolaños, and A. Heredia. 2005. Cell wall phenolics of white and green asparagus. J. Sci. Food Agr. 85:971-978.

Schwarzbach, A., M. Schreiner, and D. Knorr. 2006. Effect of cultivars and deep freeze storage on saponin content of white asparagus spears (Asparagus officinalis L.). Eur. Food Res. Technol. 222:32-35.

Selloum, L., H. Bouriche, C. Tigrine, and C. Boudoukha. 2003. Anti-inflammatory effect of rutin on rat paw oedema, and on neutrophils chemotaxis and degranulation. Exp. Toxicol. Pathol. 54:313-318.

Tsushida, T., M. Suzuki, and M. Kuroki. 1994. Evaluation of antioxidant activity of vegetable extracts and determination of some active compounds. Nippon Shokuhin Kogyo Gakkaishi 41:611-618 [in Japanese with English abstract].

Wang, M., Y. Tadmor, Q.L. Wu, C.K. Chin, S.A. Garrison, and J.E. Simon. 2003. Quantification of protodioscin and rutin in asparagus shoots by LC/MS and HPLC methods. J. Agr. Food Chem. 51:6132-6136.

Yasuda, M., M. Saiki, M. Hatiya, M. Yamada, K. Saito, T. Kumagai, I. Hara, A. Souda, and K. Terao. 2015. Functional components and antioxidative activities of the non-standard part of asparagus. Bul. Faculty Health Nutr. Nishikyushu Univ. 1:7-12 [in Japanese with English abstract].

Yeasmin, R., F. Kalemelawa, S. Motoki, H. Matsumoto, S. Yamamoto, K. Nakamatsu, and E. Nishihara. 2013. Amendment on varietal allelopathy and autotoxicity of replanted asparagus (Asparagus officinalis L.). Expt. Agr. Hort. 2:31-36.

Yeasmin, R., K. Nakamatsu, H. Matsumoto, S. Motoki, and E. Nishihara. 2014. Inference of allelopathy and autotoxicity to varietal resistance of asparagus (Asparagus officinalis L.). Austral. J. Crop Sci. 8:251-256.

Young, C.C. and T.C. Chou. 1985. Autointoxication in residues of Asparagus officinalis L. Plant Soil 85:385-393.

Zahida, I., S. Hiradate, A. Noda, S. Isojima, and Y. Fujii. 2002. Allelopathy of buckwheat: Assessment of allelopathic potential of extract of aerial parts of buckwheat and identification of fagomine and other related alkaloids as allelochemicals. Weed Biol. Manage. 2:110115.

Zhao, Q.S., J.F. Kennedy, X.D. Wang, X.F. Yuan, B. Zhao, Y.S. Peng, and Y.X. Huang. 2011 Optimization of ultrasonic circulating extraction of polysaccharides from Asparagus officinalis using response surface methodology. Intl. J. Biol. Macromol. 49:181-187. 